\title{
Geographic variation of tree height of three pine species (Pinus nigra Arn., $P$. pinaster Aiton, and $P$. pinea $L$.) gathered from common gardens in Europe and North-Africa
}

\author{
Natalia Vizcaíno-Palomar ${ }^{1}$ (D) Marta Benito Garzón ${ }^{1} \cdot$ Ricardo Alia $^{2} \cdot$ Guia Giovannelli $^{3}$ - Gerhard Huber ${ }^{4}$. \\ Sven Mutke ${ }^{2}$. Patrick Pastuszka ${ }^{5} \cdot$ Annie Raffin $^{5} \cdot$ Hassan Sbay $^{6} \cdot$ Muhidin Šeho $^{7} \cdot$ Denis Vauthier $^{8} \cdot$ Bruno Fady $^{3}$
}

Received: 21 June 2018 / Accepted: 17 July 2019/Published online: 29 July 2019

(C) INRA and Springer-Verlag France SAS, part of Springer Nature 2019

\begin{abstract}
- Key message This datapaper collects individual georeferenced tree height data from Pinus nigra Arn., P. pinaster Aiton, and P. pinea L. planted in common gardens in France, Germany, Morocco, and Spain. The data can be used to assess genetic variation and phenotypic plasticity with further applications in biogeography and forest management. The three datasets are available at https://doi.org/10.5281/zenodo.3250704 (Vizcaíno-Palomar et al. 2018a), https://doi.org/10.5281/zenodo. 3250698 (Vizcaíno-Palomar et al. 2018b), and https://doi.org/10.5281/zenodo.3250707 (Vizcaíno-Palomar et al. 2018c), and the associated metadata are available at https://metadata-afs.nancy.inra.fr/geonetwork/srv/eng/catalog.search\#/ metadata/644682d3-78c6-4fcc-af26-b1a928be7b1b, https://metadata-afs.nancy.inra.fr/geonetwork/srv/eng/catalog.search\#/ metadata/535b8ad0-9315-4d78-80bd-d0f6cbb9d0ce and https://metadata-afs.nancy.inra.fr/geonetwork/srv/eng/catalog. search\#/metadata/4cc0d2f0-00a9-42c8-aa34-fbbc647e3eb9 for $P$. nigra, $P$. pinaster and $P$. pinea, respectively.
\end{abstract}

Keywords Adaptation $\cdot$ Assisted migration $\cdot$ Genetic variation $\cdot$ Niche breadth $\cdot$ Phenotypic plasticity $\cdot$ Tree height

\section{Background}

Understanding how tree species and populations will perform under future climatic conditions has become essen-

Handling Editor: Marianne Peiffer

This article is part of the topical collection on Mediterranean pines

Natalia Vizcaíno-Palomar

natalia.vizcaino.palomar@gmail.com

Marta Benito Garzón

marta.benito-garzon@inra.fr

Ricardo Alia

alia@inia.es

Guia Giovannelli

guiagiovannelli@gmail.com

Gerhard Huber

Gerhard.Huber@aelf-pk.bayern.de

Sven Mutke

mutke@inia.es tial for sustainable forest management. Plastic responses and genetic variation are two of the processes that can generate phenotypic variation within species, and thus help populations to cope with climate change (Bolnick

\author{
Patrick Pastuszka \\ patrick.pastuszka@inra.fr \\ Annie Raffin \\ annie.raffin@inra.fr \\ Hassan Sbay \\ hassansbay@gmail.com \\ Muhidin Šeho \\ muhidin.seho@asp.bayern.de \\ Denis Vauthier \\ denis.vauthier@inra.fr \\ Bruno Fady \\ bruno.fady@inra.fr
}

Extended author information available on the last page of the article 
et al. 2011; Alberto et al. 2013; Benito Garzón et al. 2019). In forest trees, genetic diversity is generally involved in long-term adaptive responses while plasticity entails shorter responses to acclimatize (Franks and Hoffmann 2012; Chevin et al. 2013).

Pines are keystone species in many Mediterranean and European ecosystems and are often used for ecological restoration and in multi-purpose plantations. Their evolutionary history, ecology, and the ecosystem services they provide are well-known (Tapias et al. 2004; Ruiz-Benito et al. 2012; Fady 2012). However, understanding their fine-scale local adaptation patterns and how phenotypes and genotypes are associated remain a scientific challenge.

Rather recently, common garden experiments established with the aim of selecting the best forest reproductive material and to provide resources for breeding programs have been rediscovered and now reanalyzed as climate change experimental designs, see for example, Rehfeldt et al. (2002), Benito Garzón et al. (2011), O’Neill and Nigh (2011), Benito Garzón and FernándezManjarrés (2015) and Vizcaíno-Palomar et al. (2016). Common gardens provide highly valuable information for disentangling the genetic component of phenotypic trait variability, for detecting evidence of local adaptation and phenotypic plasticity. Because of this legitimate renewed interest, great efforts are currently made to digitize, harmonize, and compile datasets obtained from common gardens beyond the national scale (e.g., Robson et al. 2018).

\section{Methods}

In this datapaper, we gather individual and georeferenced phenotypic variation data of tree height from three pine species of high importance for Mediterranean and European forestry and habitat management: Pinus nigra Arn., $P$. pinaster Aiton, and $P$. pinea L. Tree height data have been generated in common gardens distributed across the species ranges where different genetic units have been grown. The genetic units included in these datasets are wild type resources whose names are those of the locality where they were collected from. In some cases, they correspond to identified seed stands and are listed in country databases as forest reproductive material. When appropriate, they can be found in the European Union FOREMATIS information system http:/ec.europa. eu/forematis/.

Specifically, we compiled data from 15 P. nigra common gardens located in France, Germany, and Spain and planted between years 1968 and 2009. The experimental design varies depending on the common garden, from a randomized complete block design ( $\mathrm{RCB}$ ) to a randomized incomplete block design, RIB, see Table 1. Likewise, the number of blocks varies from 1 to 70 , and in the case of the German common gardens, blocks have been called $\mathrm{X}, \mathrm{Y}$, and $\mathrm{Z}$. The total number of genetic units (here provenances) tested varies from 2 to 48 (Table 1). In $P$. pinaster, the data were compiled from 14 common gardens located in France, Morocco, and Spain, planted between 1966 and 1992 (Table 1). In this specific species, the data have been compiled from both provenance and progeny tests. Specifically, Pavillon and Malgaches are provenances tests, while Saint Alban, Le Bray, and La Mole are progeny-provenance tests. The experimental design depends on the common garden, being RCB or RIB; the number of blocks varies from 4 to 127 and the number of genetic units from 10 to 467 . For the data collected from the progeny tests, we only gathered the data derived from crosses between parents from the same geographic origin. Finally, in $P$. pinea, the data were compiled from 9 common gardens located in France and Spain, and planted between 1993 and 1997 (Table 1). The experimental design was RIB with 43 to 171 blocks, except in one site with $15 \mathrm{RCB}$. The number of tested genetic units (here provenances) tested varies from 26 to 38 .

Tree height data were measured on site with a telescopic ruler with a centimeter precision, see https://urgi.versailles. inra.fr/ephesis/ephesis/ontologyportal.do and specify $\mathrm{CO}_{-}$ 357:1000037 in the search button (Steinbach et al. 2013), and depending on the common garden, tree height was recorded at different tree ages. These data were always collected block by block to minimize temporal variance.

The raw data collected in the common gardens were compiled into three datasets, one for each species. The same process to generate a clean and ready dataset was repeated for each one of them. Firstly, as tree height measurements were taken in different years, we created a new variable called "Age" by subtracting the Year when the measurement was taken to the Year when the common garden was installed. This variable measures the number of years an individual tree has been growing in the common garden. Secondly, we created a code for each tree measured in a common garden. This code allows us for tracking each individual tree height over years and it is useful to assess individual tree variation. Thirdly, the geographic origin of the different genetic units (either originated in provenance tests or in progeny tests) and common gardens were georeferenced. Finally, we filtered and cleaned the dataset by eliminating negative and/or missing tree height values.

The final dimensions of each dataset were of 194,642 individual tree height data measurements for $P$. nigra with 15 common gardens and 78 different provenances, 123,801 individual tree height data measurements for $P$. pinaster with 14 common gardens and 182 different 
Table 1 Summary information of the common gardens of each pine species. The number of genetic units makes reference to the original number established in the common garden, i.e., not accounting for catastrophic events which could have depleted one or some of the genetic units

\begin{tabular}{|c|c|c|c|c|c|c|c|c|}
\hline Species & Country & $\begin{array}{l}\text { Common } \\
\text { garden }\end{array}$ & $\begin{array}{l}\text { Year of } \\
\text { plantation }\end{array}$ & Exp. design & $\begin{array}{l}\text { Number of } \\
\text { blocks }\end{array}$ & $\begin{array}{l}\text { Number of } \\
\text { trees per } \\
\text { unit plot }\end{array}$ & $\begin{array}{l}\text { Number of } \\
\text { genetic units } \\
\text { per block }\end{array}$ & $\begin{array}{l}\text { Total number } \\
\text { of genetic } \\
\text { units }\end{array}$ \\
\hline P. nigra & France & Cestas & 1974 & RIB & 7 & 6 & 7 & 15 \\
\hline P. nigra & France & Levens & 1968 & RIB & 36 & 56 & 6 & 8 \\
\hline P. nigra & France & Pomet & 1973 & RIB & 70 & 16 & 5 & 15 \\
\hline P. nigra & France & Verdun & 1968 and 1971 & RIB & 36 & 36 & 5 & 13 \\
\hline P. nigra & Germany & Bad Windsheim & 2009 & $\mathrm{RCB}$ & 3 & 50 & 10 & 10 \\
\hline P. nigra & Germany & Eglsee & 2009 & - & 1 & 50 & 2 & 2 \\
\hline P. nigra & Germany & Geibenstetten & 2009 & $\mathrm{RCB}$ & 3 & 50 & 39 & 39 \\
\hline P. nigra & Germany & Gickelhausen & 2009 & $\mathrm{RCB}$ & 3 & 50 & 21 & 21 \\
\hline P. nigra & Germany & Vilseck & 2009 & $\mathrm{RCB}$ & 3 & 50 & 48 & 48 \\
\hline P. nigra & Spain & Herrera & 1996 & $\mathrm{RCB}$ & 7 & 8 & 9 & 9 \\
\hline P. nigra & Spain & La Granja & 1996 & $\mathrm{RCB}$ & 12 & 4 & 19 & 19 \\
\hline P. nigra & Spain & Rebolleda & 1996 & RIB & 10 & 4 & $17^{2}$ & 17 \\
\hline P. nigra & Spain & Rucandio & 1996 & RIB & 7 & 8 & $7-10$ & 11 \\
\hline P. nigra & Spain & Sancedo $^{1}$ & 1996 and 1997 & $\mathrm{RCB}$ & $7-10-10$ & $8-4-4$ & $10-16-14$ & $10-16-14$ \\
\hline P. nigra & Spain & Trespaderne ${ }^{3}$ & 1996 & $\mathrm{RCB}$ & $15-9$ & 4 & $16-13$ & $16-13$ \\
\hline P. pinaster & France & Alban & 1981 & RIB & 127 & 4 & 15 & $163^{4}$ \\
\hline P. pinaster & France & Bray & 1971 & RIB & 28 & $3-100$ & $14-83$ & $408^{5}$ \\
\hline P. pinaster & France & Malgaches & 1972 & $\mathrm{RCB}$ & 4 & $33-63$ & 10 & 10 \\
\hline P. pinaster & France & Mole & 1982 & RIB & 34 & 4 & 20 & $67^{6}$ \\
\hline P. pinaster & France & Pavillon & 1970 & RIB & 80 & 13 & 4 & 16 \\
\hline P. pinaster & Morocco & Ain Rami & 1992 & $\mathrm{RCB}$ & 6 & 10 & 43 & 43 \\
\hline P. pinaster & Morocco & BV13 & 1992 & $\mathrm{RCB}$ & 6 & 36 & 33 & 33 \\
\hline P. pinaster & Morocco & Ouid Lille & 1992 & $\mathrm{RCB}$ & 8 & 10 & 42 & 42 \\
\hline P. pinaster & Spain & Acebo & 1966 & $\mathrm{RCB}$ & 4 & 16 & 52 & 52 \\
\hline P. pinaster & Spain & Cabañero & 1967 & $\mathrm{RCB}$ & 4 & 16 & 52 & 52 \\
\hline P. pinaster & Spain & Espinoso & 1967 & $\mathrm{RCB}$ & 4 & 16 & 50 & 50 \\
\hline P. pinaster & Spain & Miravete & 1966 & $\mathrm{RCB}$ & 4 & 16 & 52 & 52 \\
\hline P. pinaster & Spain & Negrillas & 1967 & $\mathrm{RCB}$ & 4 & 16 & 51 & 51 \\
\hline P. pinaster & Spain & Riofrío & 1967 & $\mathrm{RCB}$ & 4 & 16 & 53 & 53 \\
\hline P. pinea & France & Baume & 1993 & RIB & 64 & 3 & 10 & 26 \\
\hline P. pinea & France & Gaillarde & 1995 & RIB & 59 & 3 & - & 37 \\
\hline P. pinea & France & Laquina & 1995 & RIB & 66 & 3 & 10 & 37 \\
\hline P. pinea & France & Loupian & 1994 & RIB & 80 & 3 & 9 & 26 \\
\hline P. pinea & France & Treps & 1994 & RIB & 171 & 3 & - & 38 \\
\hline P. pinea & Spain & Cucalón & 1995 & RIB & 68 & 3 & 12 & 34 \\
\hline P. pinea & Spain & Quintos & 1996 & RIB & $43.5^{7}$ & 3 & 12 (b44: 6) & 29 \\
\hline P. pinea & Spain & Tordesillas & 1996 & RIB & 51 & 3 & 12 & 34 \\
\hline P. pinea & Spain & Trespaderne & 1997 & $\mathrm{RCB}$ & 15 & 3 & 29 & 29 \\
\hline
\end{tabular}

Exp. design means the type of experimental design, can be RCB or RCB. See below the meaning

RCB and RIC mean randomized complete block design and incomplete block design, respectively

${ }^{1}$ The experimental design of the common garden of Sancedo is composed of three separated plots though they belong to the same trial

${ }^{2}$ Block number 10 includes 13 provenances

${ }^{3}$ The experimental design of the common garden of Trespaderne is composed of two separated plots though they belong to the same trial

${ }^{4}$ This is a progeny and provenance test. It has a total of 163 genetic units: 154 hybrid progenies from 10 provenances, plus 9 true provenances

${ }^{5}$ This is a progeny and provenance test. It has a total of 408 genetic units: 365 progenies from 34 populations from Landes and Corsica, plus 43 provenances from Landes and Corsica

${ }^{6}$ This is a progeny and provenance test. It has a total of 467 genetic units: 25 true provenances plus 42 hybrid progenies from 10 provenances

${ }^{7}$ Due to a lack of seedlings, in the last block, the 44th, only 6 provenances were planted instead of 12

genetic units, and 56,624 individual tree height measurements for $P$. pinea with 9 common gardens and 55 different provenances. Figure 1 shows for each pine species the genetic units tested and the sites where the common gardens were established. We used the $\mathrm{R}$ version 3.2 .3 (2015-12-10) run in linux-gnu operating system for data 

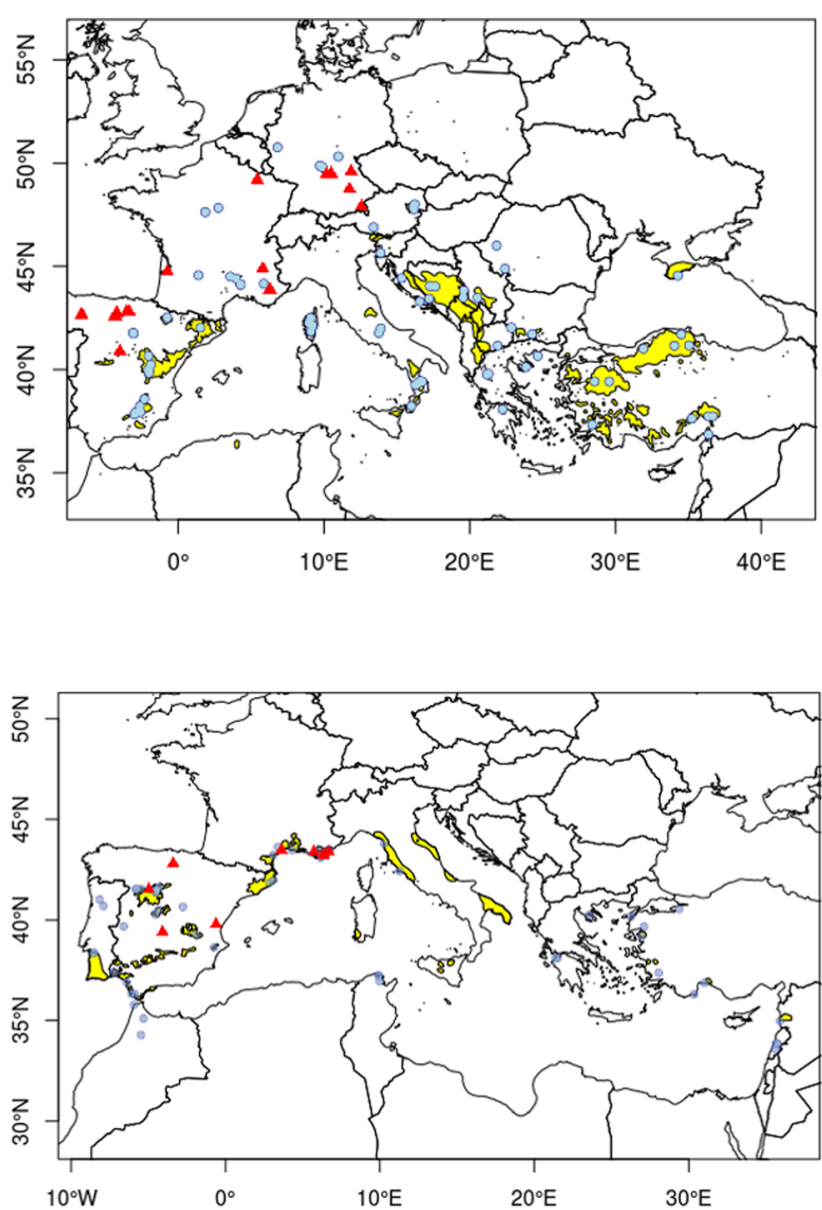

Fig. 1 The three networks of common gardens are represented in a separate map. Red triangles represent common gardens, light-blue circles represent genetic units, and yellow areas represent the natural

and file quality check and compilation. We employed basic functions, e.g., merge, rbind, spTransform, to build the datasets.

\section{Access to data and metadata description}

The three datasets are available on ZENODO, please always refer to the latest version, at https://doi.org/10.5281/zenodo. 3250704 (Vizcaíno-Palomar et al. 2018a), https://doi.org/10. 5281/zenodo.3250698 (Vizcaíno-Palomar et al. 2018b), and https://doi.org/10.5281/zenodo.3250707 (Vizcaíno-Palomar et al. 2018c) for P. nigra, P. pinaster, and P. pinea, respectively.

The data records are described in the metadata description files.

The associated metadata are available at https://metadataafs.nancy.inra.fr/geonetwork/srv/eng/catalog.search\#/ metadata/644682d3-78c6-4fcc-af26-b1a928be7b1b, https:// metadata-afs.nancy.inra.fr/geonetwork/srv/eng/catalog. search\#/metadata/535b8ad0-9315-4d78-80bd-d0f6cbb9d0ce

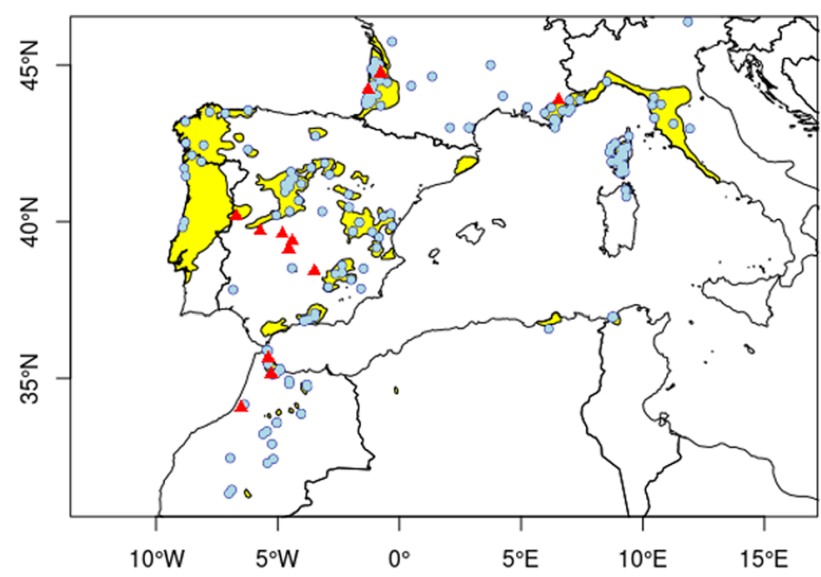

distribution of the species according to EUFORGEN source (http:// www.euforgen.org/). Top left Pinus nigra, top right Pinus pinaster, bottom left Pinus pinea

and https://metadata-afs.nancy.inra.fr/geonetwork/srv/eng/ catalog.search\#/metadata/4cc0d2f0-00a9-42c8-aa34fbbc647e 3 eb9 for $P$. nigra, $P$. pinaster and $P$. pinea, respectively.

\section{Technical validation}

Data acquisition in the field followed strict, high-quality standards, such as block-by-block measurement paths to minimize environmental and temporal variance, and the use of prefilled data loggers (when it was possible) to match previous measurements with the current status of each tree. Back-to-the-lab, quality checks such as computing minimum and maximum values, visualizing data distribution histograms, and checking differences between current and previous values were systematically used and aberrant values were removed. Part of these data have already been used successfully in previous studies (Alía et al. 1995; Harfouche et al. 1995; Climent et al. 2008; Šeho et al. 2010; Mutke et al. 2010, 2013; Benito Garzón et al. 2011; Huber and Šeho 2016; Vizcaíno-Palomar et al. 2016). 


\section{Reuse potential and limits}

The reuse of the data presented here is simple. The data files are encoded in UTF-8; hence, potential users just need to load the data and indicate this encode. For example, $\mathrm{R}$ users just need to add encoding = "UTF-8" in the function used for reading the file. If users open the file in Excel, they need to indicate the source of the data which is the UTF-8. Once the data is loaded, it is ready to be analyzed; users do not need to combine or merge any other files. Users will find that each row contains individual tree height data, defined by a set of variables (a total of 19) such as the name and the geographical position of the common garden - either provenance or progeny test- (Site_name, Long_S, Lat_S) and the name of the genetic unit and the geographical position (Prov_name, Long_P, Lat_P), year of plantation, age, etc. For further information, users can check the metadata description files. Differences among genetic units and sites should be only interpreted in the environmental context of the test sites from where the data were gathered.

Datapapers gathering common gardens (such as provenance tests) are starting to appear due to their relevance to help assess the ability of forests to deal with climate change, see for example, the recent datapaper on European beech common garden networks (Robson et al. 2018). Here, we present for the first time a datapaper collecting tree height from an extensive network of common gardens within and across countries and for three Mediterranean pine species covering European and African distribution ranges. Actually, these are powerful datasets enhancing to assess plastic responses in large climatic gradients, which is of high relevance within the climate change context; for further analysis on modeling, species ranges based on their phenotypic variation and applications for forest management as for example assisted migration programs.

Acknowledgments France: We acknowledge the invaluable help of F. Rei (INRA UEFM, Avignon, France), N. Cheval, C. Magnin, L. Moras, N. Morrisson, L. Puzos, and L. Severin (INRA UEFP, Bordeaux, France), F. Bonne, T. Paul, and V. Rousselet (INRA UEFL, Nancy, France) for data collection in French common gardens. These pine species are some of the many forest tree species managed at INRA in the GEN4X network of common gardens (see http://www.efpa.inra.fr/Outils-et-Ressources/ Systemes-d-experimentation-et-d-observation/Reseau-GEN4X). Likewise, we acknowledge the invaluable help of the Unite Expérimentale Forêt Pierroton, UEFP, which produced the material and planted, managed, and measured the trials of $P$. pinaster located in France.

Germany: We acknowledge the help of Andreas Zaiser and Christoph Sommer (Bavarian Office for Seeding and Planting) for data collection in Germany.

Morocco: We gratefully acknowledge the forest tree genetic improvement team for their assistance and dedicated involvement in every step throughout the $P$. pinaster field trials process.

Spain: We acknowledge the GENFORED team; they took field measurements, keep updated and cleaned the databases, and make possible to keep alive a great network of common gardens of different tree species.
Similarly, to Javier Gordo (Junta de Castilla y León), Aránzazu Prada (Generalitat Valenciana), and Salustiano Iglesias (MAPAMA) for data collection in P. pinea common gardens.

Contribution of the co-authors NVP compiled, cleaned, and checked the data from the three pine species and wrote the manuscript. MBG coordinated data acquisition from the three pine species and wrote the manuscript. RA coordinated the study designs and collected the data of $P$. nigra and $P$. pinaster in Spain. GG collected and compiled the data of $P$. nigra in France. GH and MS coordinated the study design of $P$. nigra in Germany and collected the data. SM collaborated in the study design of $P$. pinea in Spain, collected and checked the data. PP coordinated the study design of $P$. pinaster in France and collected the data. AR is in charge of data gathering, checking, and archiving the common gardens of $P$. pinaster in France. HS coordinated the study design of $P$. pinaster in Morocco and collected the data. DV collected data of $P$. pinea common gardens and took care of metadata and data curation for this species. BF coordinated the study design of $P$. pinea in France and collected the data. Likewise, $\mathrm{BF}$ coordinated data acquisition from the three pine species and wrote the manuscript. All authors contributed to, and approved, the final version of the manuscript.

Funding We acknowledge the funding called Investments for the future: Programme IdEx Bordeaux (France), reference ANR-10-IDEX-03-02, thanks to that MBG coordinated this datapaper and NVP worked on it. Identically, we acknowledge funding from the French Ministry of Agriculture in charge of forests and its regional bureau in Montpellier, the ANR project AMTools (ANR-11-AGRO-0005), and the AixMarseille Universite (as part of GG's PhD thesis) for the French data. In the same way, we acknowledge the support from the Spanish Ministry of Agriculture, Fishery and Environment (MAPAMA) and the regional governments of Junta de Castilla y León and Generalitat Valenciana through agreements with Universidad Politécnica de Madrid (UPM). Likewise, we acknowledge funding from the Bavarian State Ministry of Food, Agriculture and Forestry (StMELF) for the German data. The creation of the network of $P$. pinea common gardens was made possible by the support given from FAO Silva Mediterranea (http://www.fao.org/ forestry/silva-mediterranea/en/). INRA funded the creation and maintenance of the French experimental network of common gardens (GEN4X), as well as the development and implementation of the information system archiving its data, GnpIS (https://urgi.versailles.inra. $\mathrm{fr} /$ Tools/GnpIS). P. pinea data collected in the future will be archived on GnpIS at: https://urgi.versailles.inra.fr/ephesis/ephesis/viewer.do\# dataResults). INIA funded the Spanish network by successive projects OT03-002, AT2010-007, AT2013-004, and RTA2013-00011. Finally, this publication is part of a project that has received funding from the European Union's Horizon 2020 research and innovation programmer under grant agreement no. 676876 (GenTree).

\section{Compliance with ethical standards}

Conflict of interest The authors declare that they have no conflict of interest.

\section{References}

Alberto FJ, Aitken SN, Alía R et al (2013) Potential for evolutionary responses to climate change - evidence from tree populations. Glob Chang Biol 19:1645-1661. https://doi.org/10.1111/gcb.12181

Alía R, Gil L, Pardos JA (1995) Performance of 43 Pinus pinaster Ait. provenances on 5 locations in Central Spain. Silvae Genet 44:75-81 
Benito Garzón M, Fernández-Manjarrés J (2015) Testing scenarios for assisted migration of forest trees in Europe. New For 46:979-994

Benito Garzón M, Alía R, Robson TM, Zavala MA (2011) Intra-specific variability and plasticity influence potential tree species distributions under climate change. Glob Ecol Biogeogr 20:766-778. https://doi. org/10.1111/j.1466-8238.2010.00646.x

Benito Garzón M, Robson TM, Hampe A (2019) $\Delta$ TraitSDM: Species distribution models that account for local adaptation and phenotypic plasticity. New Phytol 222:1757-1765. https://doi.org/10.1111/nph. 15716

Bolnick DI, Amarasekare P, Araújo MS, Bürger R, Levine JM, Novak M, Rudolf VHW, Schreiber SJ, Urban MC, Vasseur DA (2011) Why intraspecific trait variation matters in community ecology. Trends Ecol Evol 26:183-192

Chevin LM, Collins S, Lefèvre F (2013) Phenotypic plasticity and evolutionary demographic responses to climate change: taking theory out to the field. Funct Ecol 27:967-979. https://doi.org/10.1111/j. 1365-2435.2012.02043.x

Climent J, Prada MA, Calama R, Chambel MR, de Ron DS, Alía R (2008) To grow or to seed: ecotypic variation in reproductive allocation and cone production by young female Aleppo pine (Pinus halepensis, Pinaceae). Am J Bot 95:833-842. https://doi.org/10. 3732/ajb.2007354

Fady B (2012) Biogeography of neutral genes and recent evolutionary history of pines in the Mediterranean Basin. Ann For Sci 69:421428. https://doi.org/10.1007/s13595-012-0219-y

Franks SJ, Hoffmann AA (2012) Genetics of climate change adaptation. Annu Rev Genet 46:185-208. https://doi.org/10.1146/annurevgenet-110711-155511

Harfouche A, Baradat P, Durel C, Pommery J (1995) Variabilité intraspécifique chez le pin maritime (Pinus pinasterAit.) dans le sud-est de la France. I. Variabilité des populations autochtones et des populations de l'ensemble de l'aire de l'espèce. Ann For Sci 52: 307-328. https://doi.org/10.1051/forest: 19950402

Huber G, Šeho M (2016) Die Schwarzkiefer - eine Alternative für warmtrockene Regionen. LWF aktuell 110:17-20

Mutke S, Gordo J, Chambel MR, Prada MA, Álvarez D, Iglesias S, Gil L (2010) Phenotypic plasticity is stronger than adaptative differentiation among Mediterranean stone pine provenances. For Syst 19:354. https://doi.org/10.5424/fs/2010193-9097

Mutke S, Gordo J, Khouja M, Fady B (2013) Low genetic and high environmental diversity at adaptive traits in Pinus pinea from provenance tests in France and Spain. Options Méditerranéennes A 105: 73-79

O’Neill GA, Nigh G (2011) Linking population genetics and tree height growth models to predict impacts of climate change on forest production. Glob Chang Biol 17:3208-3217. https://doi.org/10. 1111/j.1365-2486.2011.02467.x

Rehfeldt GE, Tchebakova NM, Parfenova YI, Wykoff WR, Kuzmina NA, Milyutin LI (2002) Intraspecific responses to climate in Pinus sylvestris. Glob Chang Biol 8:912-929. https://doi.org/10.1046/j. 1365-2486.2002.00516.x

Robson TM, Benito Garzón M, Beech COSTe52 database consortium (2018) Phenotypic trait variation measured on European genetic trials of Fagus sylvatica L. Sci Data 5:180149. https://doi.org/10. 1038/sdata.2018.149

Ruiz-Benito P, Gómez-Aparicio L, Zavala MA (2012) Large-scale assessment of regeneration and diversity in Mediterranean planted pine forests along ecological gradients. Divers Distrib 18:1092-1106

Šeho M, Kohnle U, Albrecht A, Lenk E (2010) Wachstumsanalysen von vier Schwarzkiefer-Provenienzen auf trockenen Standorten in Baden-Württemberg. Allg Forst- und Jagdzeitung 181:104-116

Steinbach D, Alaux M, Amselem J, Choisne N, Durand S, Flores R, Keliet AO, Kimmel E, Lapalu N, Luyten I, Michotey C, Mohellibi N, Pommier C, Reboux S, Valdenaire D, Verdelet D, Quesneville H (2013) GnpIS: an information system to integrate genetic and genomic data from plants and fungi. Database (Oxford) 2013:bat058. https://doi.org/10.1093/database/bat058

Tapias R, Pardos JA, Gil L, Climent J (2004) Life histories of Mediterranean pines. Plant Ecol 171:53-68

Vizcaíno-Palomar N, Ibáñez I, González-Martínez SC, Zavala MA, Alía R (2016) Adaptation and plasticity in aboveground allometry variation of four pine species along environmental gradients. Ecol Evol 6: 7561-7573. https://doi.org/10.1002/ece3.2153

Vizcaíno-Palomar N, Benito Garzón M, Alía R, et al (2018a) Geographic variation of tree height of Pinus nigra Arn. gathered from common gardens in Europe. V3. ZENODO. [Dataset]. https://doi.org/10. 5281/ZENODO.3250704

Vizcaíno-Palomar N, Benito Garzón M, Alía R, et al (2018b) Geographic variation of tree height of Pinus pinaster Aiton gathered from common gardens in Europe and North-Africa V3. ZENODO. [Dataset]. https://doi.org/10.5281/zenodo.3250698

Vizcaíno-Palomar N, Benito Garzón M, Mutke S, et al (2018c) Geographic variation of tree height of Pinus pinea L. gathered from common gardens in Europe. V3. ZENODO. [Dataset]. https://doi. org/10.5281/ZENODO.3250707

Publisher's note Springer Nature remains neutral with regard to jurisdictional claims in published maps and institutional affiliations.

\section{Affiliations}

\section{Natalia Vizcaíno-Palomar ${ }^{1}$ (D) Marta Benito Garzón ${ }^{1} \cdot$ Ricardo Alia $^{2} \cdot$ Guia Giovannelli $^{3} \cdot$ Gerhard Huber $^{4}$. Sven Mutke ${ }^{2} \cdot$ Patrick Pastuszka $^{5} \cdot$ Annie Raffin $^{5} \cdot$ Hassan Sbay $^{6} \cdot$ Muhidin Šeho $^{7} \cdot$ Denis Vauthier $^{8} \cdot$ Bruno Fady $^{3}$}

1 BIOGECO, INRA, Univ. Bordeaux, 33615 Pessac, France

2 INIA, Forest Research Centre \& iuFOR UVa-INIA, Ctra La Coruña km 7.5, 28040 Madrid, Spain

3 INRA Unité de recherches Ecologie des Forêts Méditerranéennes, UR629 (URFM), Avignon, France

4 Bayerisches Staatsministerium für Ernährung, Landwirtschaft und Forsten (StMELF), Ludwigstraße 2, 80539 München, Germany
5 UEFP, INRA, 33610 Cestas, France

6 Centre de Recherche Forestière, Avenue Omar Ibn Al Khattab, BP 763, 10050 Rabat Agdal, Morocco

7 Bayerisches Amt für forstliche Saat-und Pflanzenzucht, Forstamtsplatz 1, 83317 Teisendorf, Germany

8 INRA Unité expérimentale Entomologie et Forêt Méditerranéenne, UR348 (UEFM), Avignon, France 